\title{
Analysis of Clinicopathological Factors Affecting the Prognosis of Advanced Cervical Squamous Cell Carcinoma Treated With Chemoradiotherapy
}

\section{Zhenhua Zhang}

The Affiliated Hospital of Southwest Medical University

Qian Dai

Southwest Medical University https://orcid.org/0000-0003-0768-3302

Yueshui Zhao

Southwest Medical University

Shixin Xiang

Southwest Medical University

Mintao Xiao

Southwest Medical University

Fukuan Du

Southwest Medical University

Huijiao Ji

Southwest Medical University

\section{Parham Jabbarzadeh Kaboli}

Southwest Medical University

Xu Wu

Southwest Medical University

Mingxing Li

Southwest Medical University

\section{Qinglian Wen}

The Affiliated Hospital of Southwest Medical University

Jing Li

The Affiliated Hospital of Southwest Medical University

\section{Zhangang Xiao}

Southwest Medical University

\section{Jing Shen}

Southwest Medical University

\section{Li Li ( $\square$ lili@gxmu.edu.cn )}

The Affiliated Hospital of Southwest Medical University 
Research

Keywords: Chemoradiotherapy, Sensitivity, Prognostic factors, Cervical squamous cell carcinoma

Posted Date: December 10th, 2020

DOI: https://doi.org/10.21203/rs.3.rs-122171/v1

License: (c) (i) This work is licensed under a Creative Commons Attribution 4.0 International License. Read Full License 


\section{Abstract}

Objective

The clinical data of more than 900 patients with locally advanced cervical squamous cell carcinoma diagnosed for the first time and treated with radical chemoradiotherapy in recent 9 years were analyzed to find important prognostic factors in advanced cervical squamous cell carcinoma, and provide statistics for future research.

Method

The patients were divided into two groups: chemoradiotherapy resistant group and chemoradiotherapy sensitive group. The survival rate and prognostic factors were analyzed using $\mathrm{R}$ language.

Result

There was considerable difference in overall survival (OS) and progression free survival (PFS) between the two groups, of which the chemoradiotherapy sensitive group is about 10 months longer than the resistant group. In the chemoradiotherapy resistant group, there were more patients with higher staging, higher NLR(neutrophil to lymphocyte ratio), lymph node metastasis, and a total radiotherapy time of more than 8 weeks. For the factors affecting chemoradiotherapy sensitivity, radiotherapy alone rather than simultaneous chemoradiotherapy, late tumor stage, lymph node metastasis and a total time of radiotherapy more than 8 weeks predicts lower sensitivity.

Conclusion

The main clinical factors affecting chemoradiotherapy sensitivity were tumor stage, lymph node metastasis and the total time of radiotherapy. Chemoradiotherapy sensitivity, tumor diameter, NLR, PLR (platelet to lymphocyte ratio) and total time of radiotherapy were independent prognostic factors for OS and PFS.

\section{Introduction}

Cervical cancer is one of the most common malignant tumors of female genital system, which is second only to breast cancer in the incidence of female malignant tumors in the world. It is the seventh in the incidence of all malignant tumors and the third leading cause of cancer death among women, with $78 \%$ of patients in middle-income countries. In China, there are 135,000 new incident cases every year. The latest statistics showed that 106,000 new incident cases in 2018[1]. Incidents of cervical cancer tend to be younger. The peak incidence was 45-49 years old[2]. The incidence in urban areas is higher than that in rural areas, which may be related to many factors of HPV infection. Although with the widespread application of cervical cytology screening technology, cervical cancer can be detected and treated early, yet early symptoms are not obvious. The patients do not pay enough attention to their health and lack 
screening knowledge. About $2 / 3$ of the patients are in the advanced stage of the disease when they are diagnosed.

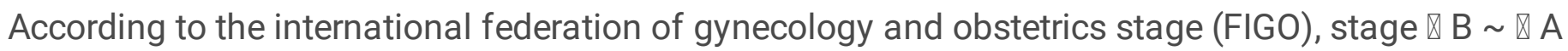
cervical cancer is defined as locally advanced cervical cancer (LACC). Squamous cell carcinoma accounts for about $75 \%$ of the pathological types of cervical cancer, so advanced cervical squamous cell carcinoma accounts for the vast majority. The current standard of treatment for advanced cervical squamous cell carcinoma is radical concurrent chemoradiotherapy. Compared with early cervical carcinoma, the curative effect of advanced cervical carcinoma was significantly lower. At present, the average 5 -year overall survival rate is $40 \%-50 \%, 29 \%-38 \%$ of the failure are uncontrolled or relapsed, and the 5 -year survival rate of patients with recurrence is only $3.8 \% \sim 13.0 \%[3]$. It is concluded that uncontrolled or recurrent tumor was the principal factor affecting the survival of patients. How to increase the local control rate and reduce the recurrence rate is an important research direction to improve the curative effect of advanced cervical cancer. Therefore, knowing the current efficacy for treatment of patients with advanced cervical squamous cell carcinoma and its influencing factors can lead to better understanding of the disease, so as to guide the therapy regimen and improve the prognosis of patients.

At present, a large number of studies at home and abroad have focused on the basic and clinical research of advanced cervical cancer, including survival analysis, prognostic factor analysis, recurrence or uncontrolled analysis, and the analysis of factors related to lymph node metastasis [4-6]. Throughout these studies, the quality of articles is different, the number of cases enrolled in most studies is small and the results of different research units are not the same. Moreover some studies are conducted a long time, when the radiotherapy technology of two-dimensional era is mostly used in radiotherapy. With the advance of modern radiotherapy technology, the use of three-dimensional conformal or intensity modulated radiotherapy may further improve the curative effect.

For this reason, we collected more than 900 cases in the past 9 years for retrospective analysis, and used $\mathrm{R}$ language to statistically analyze the survival rate and prognosis factors, in order to provide statistics for the prognostic factors of advanced cervical squamous cell carcinoma and to guide the direction of future research.

\section{Materials And Methods}

\section{Clinical data}

Clinical data of patients with locally advanced cervical squamous cell carcinoma diagnosed for the first time and treated with radical chemoradiotherapy were collected in the Department of Gynecology and Oncology of Guangxi Medical University Affiliated Tumor Hospital and the affiliated Hospital of

Southwest Medical University from January 2007 to September 2015. The patients were divided into two groups [7]. The standard of radiochemotherapy sensitive group was that 6 months after radiochemotherapy the tumor disappeared, the cervix prototype recovered, the texture was uniform, the hardness was normal, the induration of the tissue adjacent to the uterus was small. the texture became 
soft and the elasticity improved. The standard of radiochemotherapy resistance group was that local cervical masses still exist or new lesions appear within 6 months after radiochemotherapy.

\section{Inclusion and exclusion criteria}

1. Inclusion criteria:

1. Some pathological tissues are clearly diagnosed as cervical squamous cell carcinoma;

2. First diagnosed patient;

3. A patient between the ages of 18 and 80 ;

4. IIB stage and above are staged by FIG01995 and FIGO 2009, and no distant metastasis is confirmed by imaging examination;

5. ECOG have a score of 0 to 2 ;

6. Patients with normative radical radiotherapy, including external irradiation and intracavity afterloading irradiation;

7. Patients with complete case and follow-up data;

2. Exclusion criteria:

1. Other pathological types of cervical cancer;

2. Patients with recurrence or distant metastasis;

3. Patients who have not completed the radiotherapy, such as those who have not received intracavitary irradiation, or those who have not completed the intracavitary brachytherapy as planned;

4. Patients with surgical treatment related to the treatment of cervical cancer, such as those who completed lymph node dissection before radiochemotherapy, but excluding those who received interventional hemostasis and interventional infusion chemotherapy.

\section{Treatment method}

\section{External irradiation:}

After fixed by body network or other methods, CT scanning or x-ray simulation positioning, the whole pelvic external irradiation was given. The radiation dose was $45-50 \mathrm{~Gy} / 1.8-2 \mathrm{~Gy} / 5 \mathrm{w}$. The dose for patients with lymph node metastasis could be raised to 60-70 Gy. There are three kinds of radiotherapy methods that can be selected.

(1) Conventional radiotherapy: including pelvic field irradiation and pelvic box irradiation. Pelvic field irradiation is that according to the scope of the tumor, including the lower abdomen and the pelvic cavity, the anterior and posterior fields are irradiated vertically, the upper boundary of the field is at the level of the iliac crest (waist 4,5 ), the lower boundary is at the inferior margin of the pubic symphysis, and both 
sides are near the anterior superior iliac spine. Pelvic box irradiation is pelvic field irradiation and two lateral fields. Bilateral anterior fields reach the pubic symphysis and the posterior reaches the level of the second to third sacral vertebrae. If the mass is large, the posterior edge can reach the level of the third to fourth sacral vertebrae, and the small intestine should be protected at the same time. (2) Conformal radiotherapy: It adopts three-dimensional conformal technology, The range of radiotherapy is CTV(clinical target volume), cervix, uterine body, upper vaginal segment, parauterine tissue, lymph node drainage area. Extended PTV(Planned target volum), as the planning target area, can better protect normal organs. (3) Intensity modulated radiotherapy: The range of radiotherapy is the same as that of conformal radiotherapy, the radiation dose is the same as before, the maximum dose and minimum dose in the target area do not exceed the prescription dose $\pm 10 \%$, and the tolerance dose limit for organ at risk (OAR) is as follows: maximum dose of spinal cord $<40 \mathrm{~Gy}$, kidney $\mathrm{V} 20<30 \%$, small intestinal V $40<50 \%$, rectal $\mathrm{V} 50<50 \%$, bladder $\mathrm{V} 50<50 \%$, femoral head $\mathrm{V} 30<50 \%$, pelvic bone $\mathrm{V} 30<50 \%$. OAR maximum dose is lower than the prescription dose. Extended field irradiation is given according to the condition of tumor or lymph node metastasis.

\section{Brachytherapy}

Depending on the situation of tumor regression, brachytherapy begins at $30 \mathrm{~Gy}$ after external irradiation or end of external irradiation. High dose rate $\operatorname{~Ir~}^{192}$ afterloading machine is used and intracavitary brachytherapy is performed with the uterine cavity and two vaginal applicator by the Manchester method. External irradiation is not conducted on the day of treatment. The prescription dose of two-dimensional radiotherapy is A point $600-700 \mathrm{~Gy} /$ times, $1-2$ times a week, a total of 4-5 times, making the total biological dose at point $A \geq 70 \mathrm{~Gy}$. Patients who use three-dimensional technology make HR-CTV $\geq 70-$ $85 \mathrm{~Gy}$ according to the disease.

\section{Chemotherapy}

Depending on the patient's situation, radiotherapy can be combined with chemotherapy any way.

1. Radiotherapy alone: The above-mentioned radiotherapy methods are used alone, those without chemotherapy.

2. Concurrent chemoradiotherapy: Concurrent chemotherapy is given during radiotherapy, including platinum-based chemotherapy, cisplatin weekly regimen that is cisplatin (DDP) $40 \mathrm{mg} / \mathrm{m} 2$, ivp, qw and cisplatin 3-week regimen that is DDP $75 \mathrm{mg} / \mathrm{m} 2$,ivp,q3w; or other chemotherapeutic drugs, and platinum-based 2-drug combined 3-week chemotherapy.

3. Adjuvant chemotherapy: It includes neoadjuvant chemotherapy before radiotherapy and adjuvant chemotherapy after radiotherapy. At present, whether to use adjuvant chemotherapy is controversial, and there is no standard chemotherapy regimen. In this study, all platinum-based combination chemotherapy regimens are incorporated into the analysis, focusing only on the impact of the course of chemotherapy. 


\section{Follow-up}

The follow-up deadline is December 2016. The main contents are as follows: hospitalization number, name, age, clinical FIGO stage, tumor diameter, $\mathrm{Hb}$ value before treatment, NLR before treatment, PLR, whether there is lymph node metastasis, total radiotherapy time, radiotherapy method, radiotherapy dose, chemotherapy regimen and course, efficacy at the end of radiotherapy, OS (overall survival is the time interval from the beginning of treatment to death or the end of follow-up), PFS (progression-free survival is the interval from the beginning of treatment to the end of tumor progression or follow-up) etc.

\section{Statistical analysis}

All the data were analyzed by R language 3.4.3 Software (https: //CRAN.R-project.org/package=survival.). The Kaplan-Meier method was used to draw the survival curve and survival rate, logarithmic rank test (log-rank method) was used to test the difference of survival rate among different groups, and chi-square test was used to obtain P value. The critical values of NLR and PLR were determined by ROC curve method. The proportional hazard regression model (COX regression model) was used for univariate and multivariate analysis, and the confidence interval of $95 \%$ of the risk ratio zone was used. All the data were analyzed by bilateral test, $\mathrm{P}<0.05$ indicates that there was a statistical difference.

\section{Results}

\section{General information of patients}

All 965 patients were followed up, including 769 cases in the Guangxi Medical University Affiliated Tumor Hospital and 195 cases in the affiliated Hospital of Southwest Medical University. Among these patients, 73 patients were lost to follow-up. The rate of lost to follow-up was $18 \%$. The basic information of all patients was shown in Table 1. The ratio of the chemoradiotherapy sensitive group (738 cases) and the chemoradiotherapy resistance group (227 cases) was 3.25\%, and the chemoradiotherapy resistance group accounts for $23.52 \%$ of all patients. Compared with the chemoradiotherapy sensitive group, the mortality rate of the chemoradiotherapy resistant group was significantly higher. There were considerable differences in OS and PFS between the two groups, and that of the chemoradiotherapy sensitive group was about 10 months longer than the resistant group. In the chemoradiotherapy resistance group, there were more patients with higher staging, higher NLR, more patients with lymph node metastasis, and more patients with a total radiotherapy time of more than 8 weeks. Patients in the chemoradiotherapy resistance group had younger age, larger tumor diameter, higher PLR, lower number of concurrent chemotherapy course, and low number of adjuvant chemotherapy course, and there was no significant difference between the two hospitals.

\section{Factors affecting the sensitivity to chemoradiotherapy}

Univariate analysis showed that concurrent chemoradiotherapy increased the sensitivity of chemoradiotherapy by about $37 \%$ compared with radiotherapy alone $(0.63(0.42-0.96, p=0.027))$. Patients 
with later tumor stage greater than or equal to IIIB stage had reduced their sensitivity to chemoradiotherapy compared with patients with IIB-IIIA by about 1.55 times $(1.55(1.07-2.30, p=0.025)$ ). Patients, with lymph node metastasis had decreased sensitivity to chemoradiotherapy by 1.96 times (1.96 (1.42-2.70, $p<0.001))$, and those who received radiotherapy for more than 8 weeks had reduced sensitivity of chemoradiotherapy by about 1.51 times $(1.51(1.10-2.09, \mathrm{p}=0.011))$. Multivariate analysis showed that radiotherapy time more than 8 weeks was independent influencing factor, which reduced the sensitivity of chemoradiotherapy by about 2.11 times $(2.11(1.16-3.96, p=0.017))$. Other factors including age, tumor stage, chemotherapeutic drugs and even different synchronous chemotherapeutic drugs, whether to use adjuvant chemotherapy and different adjuvant chemotherapeutic drugs and improved technique of radiotherapy showed no statistical difference in univariate and multivariate analysis of influencing factors related to chemoradiotherapy sensitivity. (Table 2)

\section{Threshold of NLR and PLR for predicting curative effect}

The ROC curve was drawn taking NLR and PLR before treatment as test variables and treatment efficacy as state variables. The maximum value of the sum of sensitivity and specificity was taken as the best critical value. The best critical value of NLR for predicting the efficacy of chemoradiotherapy was 2.91, the sensitivity and specificity were 0.505 and 0.610 respectively. The area under the curve was 0.561(Fig.1A). The best critical value of PLR for predicting the efficacy of chemoradiotherapy was 174.8, the sensitivity and specificity were 0.498 and 0.587 respectively. The area under the curve was 0.531 (Fig.1B). ROC curve indicates that there was no diagnostic value. Although there were differences in NLR and PLR between chemoradiotherapy sensitive group and resistant group (Fig.1C), they were not enough to predict the curative effect.

\section{Survival analysis}

At the end of the follow-up, 647 of the 965 patients were alive. Based on the survival results, the 3-year survival rates of the chemoradiotherapy sensitive group and the chemoradiotherapy resistance group were $90.02 \%$ and $54.08 \%$, respectively, and the 5 -year survival rates were $79.09 \%$ and $42.03 \%$, respectively. The 5 -year survival rate of the chemoradiotherapy sensitive group was about $40 \%$ higher than that of the chemoradiotherapy resistance group. There was considerable statistical difference $(\mathrm{P}<$ 0.01 ), in OS and PFS, between the two groups. The survival rate in the chemoradiotherapy sensitive group was significantly higher than that in the chemoradiotherapy resistant group. ( Fig.2)

Because of the large age span of the statistical data, a stratified analysis of different ages showed that there are differences in survival rates among different chemoradiotherapy sensitive groups in the same age group, but there was no significant difference between different ages in the same group (Fig.2).

\section{Clinical factors affecting chemoradiotherapy OS}

There was no significant difference in total OS of advanced cervical squamous cell carcinoma between the two hospital. Univariate analysis showed that sensitivity to chemoradiotherapy, tumor diameter, 
hemoglobin, NLR, PLR and lymph node metastasis were influencing factors of OS, while age, tumor stage, times of concurrent chemotherapy and times of adjuvant chemotherapy were not factors affecting OS. The results of multivariate analysis showed that sensitivity to chemoradiotherapy, tumor diameter, NLR, PLR and total time of radiotherapy were independent factors affecting OS, while hemoglobin level and lymph node metastasis were not independent prognostic factors.

It can be seen that the sensitivity to chemoradiotherapy can be used as an independent prognostic index., and the risk of death in the chemoradiotherapy resistant group was 6.48 times higher than that in the chemoradiotherapy sensitive group $(\mathrm{HR}=6.48,95 \% \mathrm{Cl}=4.7-8.95, \mathrm{P}<0.001)$. Tumor diameter was also an independent prognostic indicator. The risk of tumor diameter larger than $4 \mathrm{~cm}$ was 1.59 times higher than that of below $4 \mathrm{~cm}(\mathrm{HR}=1.59,95 \% \mathrm{Cl}=1.15-2.20, \mathrm{P}=0.005)$. For every $1 \%$ increase in NLR, the risk level increased by $8 \%(\mathrm{HR}=1.08,95 \% \mathrm{Cl}=1.01-1.15, \mathrm{P}=0.028)$. For every $0.2 \%$ increase in $\mathrm{PLR}$, the risk increased by $0.2 \%(\mathrm{HR}=1.002,95 \% \mathrm{Cl}=1.000-1.004, \mathrm{P}=0.005)$. Compared with patients whose total time of radiotherapy was less than or equal to 8 weeks, the risk of patients with total time of radiotherapy greater than 8 weeks was 1.53 times higher( $\mathrm{HR}=1.53,95 \% \mathrm{Cl}=1.10-2.14, \mathrm{P}=0.012)$. (Table 3)

\section{Clinical risk factors of chemoradiotherapy PFS}

The influence of clinical factors on PFS was similar to that on OS, and there was no significant difference between the two hospital. Univariate analysis showed that the sensitivity to chemoradiotherapy, tumor diameter, hemoglobin, NLR, PLR and lymph node metastasis were the influencing factors of PFS, while age, tumor stage, simultaneous chemotherapy and adjuvant chemotherapy were not the factors affecting PFS. The results of multivariate analysis showed that sensitivity to chemoradiotherapy, tumor diameter, NLR, PLR and total time of radiotherapy were independent factors affecting PFS, while hemoglobin level and lymph node metastasis were not independent prognostic factors.

It can be seen that the sensitivity to chemoradiotherapy can be used as an independent index, and the risk course of death in the chemoradiotherapy resistant group was 7.18 times higher than that in the chemoradiotherapy sensitive group ( $\mathrm{HR}=7.18,95 \% \mathrm{Cl}=5.35-9.64, \mathrm{P}<0.001)$. Tumor diameter was also an independent prognostic indicator, and the risk of tumor diameter larger than $4 \mathrm{~cm}$ was 1.52 times higher than below $4 \mathrm{~cm}(\mathrm{HR}=1.52,95 \% \mathrm{Cl}=1.10-2.10, \mathrm{P}=0.1063)$. For every $1 \%$ increase in NLR, the risk level increased by $7 \%(\mathrm{HR}=1.07,95 \% \mathrm{Cl}=1.00-1.15, \mathrm{P}=0.036)$. For every $0.2 \%$ increase in $\mathrm{PLR}$, the risk increased by $0.2 \%(\mathrm{HR}=1.003,95 \% \mathrm{Cl}=1.002-1.004, \mathrm{P}=0.009)$. Compared with patients with total radiotherapy time less than or equal to 8 weeks, the risk of patients with total radiotherapy time greater than 8 weeks was 1.54 times higher $(\mathrm{HR}=1.54,95 \% \mathrm{Cl}=1.11-2.16, \mathrm{P}=0.011)$. (Table 4)

\section{Discussion}

From the results of this study, it can be seen that the 5-year survival rate of the chemoradiotherapy sensitive group was about $40 \%$ higher than that of the chemoradiotherapy resistant group. Chemoradiotherapy sensitivity had a significant influence on OS and PFS, and can be used as an independent prognostic index for the curative effect of advanced cervical squamous cell carcinoma. In 
this study, the patients were divided into chemoradiotherapy resistant group and sensitive group. There were differences in tumor stage, hemoglobin level before radiotherapy, NLR value before radiotherapy, lymph node metastasis and total time of radiotherapy between the two groups. However, there was no significant difference in age, tumor diameter, PLR value, the number of courses of concurrent chemotherapy and the number of courses of adjuvant chemotherapy between the two groups. The analysis of the factors affecting the sensitivity to chemoradiotherapy showed that only the patients with radiotherapy alone, late tumor stage, lymph node metastasis and the total time of radiotherapy more than 8 weeks were the unfavorable factors to reduce the sensitivity to chemoradiotherapy. However, multivariate analysis showed that only total time of radiotherapy more than 8 weeks was an independent factor.

Similar to this study, articles on uncontrolled recurrence of advanced cervical squamous cell carcinoma obtained similar conclusions. Chen CC[8] showed that lymph node metastasis and low hemoglobin level before treatment were uncontrolled risk factors for tumor recurrence. There was no difference in tumor diameter between chemoradiotherapy sensitivity. The results reported in most other literatures in this study were inconsistent[9]. In this study, the proportion of tumor diameter $\geq 4 \mathrm{~cm}$ in chemoradiotherapy sensitive group and chemoradiotherapy resistant group was similar. It may be due to the subjectivity of the doctor to judge the diameter of the tumor and whether to use imaging examination, so that the size of the judgment was different from the actual size. The average course of concurrent chemotherapy between the two groups was about 1.5. Whether it was related to the choice of chemotherapeutic drugs, the general condition of patients, complications or other factors needs more in-depth and detailed research.

\section{Age}

The latest epidemiological survey on the incidence of cervical cancer in China showed that incidents of cervical cancer tended to be younger, and the peak age was 45-49 years old[2]. Cervical cancer patients less than 35 years old were usually defined as young cervical cancer, but according to the clinical data of this study, there were only 27 patients under 35 years old, accounting for $2.8 \%(27 / 965)$. This may be related to the fact that the pathological type of the patients we had chosen was squamous cell carcinoma and young patients were more likely to have non-squamous cell carcinoma[10]. Among young patients, the proportion of cervical adenocarcinoma and neuroendocrine carcinoma was higher, and the incidence was on the rise. They also prone to lymph node and distant metastasis, and the therapeutic effect was poor. [11]. In the study of Ruey-Jien Chen et al.[12], it is found that the older the patient at the time of diagnosis the poorer the prognosis. However, the results obtained in our study were comparable to those in most literature, that there was no correlation between age and survival rate. The results of Liu,Y.M.[13] showed that there was no difference in OS and PFS, but there was a significant difference in the number of cases between the two groups in their study. There were 90 patients older than 40 years old and only 8 cases less than 40 years old. Kastritis E.[14]also showed that age was not related to prognosis. OS from 35 to 70 years old was 14.5 months. OS for patients older than 70 years old were 10 months and those less than 35 years old were 9 months. This may be related to age grouping and the 
study included some patients with recurrence or metastasis, resulting in biased results. Combining our result and the literature, age may not be an independent prognostic factor for patients with advanced cervical squamous cell carcinoma treated with chemoradiotherapy.

\section{Clinical stage}

There is no doubt that the clinical stage is directly related to the curative effect. To a certain extent, the clinical stage reflects the severity of the disease. It is an independent factor of prognosis. The earlier the clinical stage, the higher the 5-year survival rate. Binbin, T et al. [15] found that 5 years after concurrent chemoradiotherapy, the OS and PFS of patients with stage IIB were $75.9 \%$ and $71.7 \%$, respectively, and those of stage III and above are $52.9 \%$ and $42.8 \%$, respectively. A Korean study [16] find that 5-year survival rates after receiving concurrent chemoradiotherapy were $71.5 \%$ for patients with stage IIB, $44.9 \%$ for patients with stage III and $20.9 \%$ for patients with stage IV A. In our study, univariate and multivariate analysis suggested that staging was a factor affecting OS in chemoradiotherapy of advanced cervical squamous cell carcinoma, but staging was not a factor affecting PFS. This may be due to the fact that in this study the specimens above stage III accounted for about 77.2\%. Moreover, the staging of the tumor depended on the doctor's gynecological examination experience and had a certain degree of subjectivity. Differences in technical level and equipment may also influence staging.

\section{Tumor diameter}

In the early stage of cervical cancer, Horn.LC et al. [17] showed that tumor size was an independent factor affecting the prognosis of patients, which was the same as our study. Univariate analysis and multivariate analysis showed that tumor diameter was a factor affecting OS and PFS. Research by Teh $\mathrm{J}$ et al.[18] showed that tumor diameter was an independent prognostic factor for the efficacy of concurrent chemoradiotherapy in advanced cervical squamous cell carcinoma. In patients with tumor diameter $\geq$ $4 \mathrm{~cm}$ and $<4 \mathrm{~cm}$, the 5 -year OS was $86.3 \%$ and $59.3 \%$, respectively, and the 5 -year DFS was $55.3 \%$ and $69.3 \%$, respectively. However, tumor diameter was not an independent influencing factor in multivariate analysis. Moreover, the analysis of the tumor diameter data was partly derived from CT scans, which may had some errors. Some studies [5] found that the 5-year OS of tumor diameter $>4 \mathrm{~cm}$ and $<4 \mathrm{~cm}$ was $63 \%$ and $75 \%$, respectively, while LRFS (local recurrence-free survival time) was $44 \%$ and $60 \%$, respectively, but there was no difference between 5-year DFS (tumor-free survival stage) between the two groups, and multivariate analysis did not showed that it was an independent factor affecting prognosis. But Endo,D. et al. [19]analyzed the prognostic factors of patients with advanced cervical cancer treated with concurrent chemoradiotherapy. Both univariate and multivariate analyses showed a 2.3-fold increased risk for tumor diameter $\geq 6 \mathrm{~cm}$, which was associated with poor prognosis.

From the above analysis, it can be seen that the tumor diameter of advanced cervical squamous cell carcinoma based on $4 \mathrm{~cm}$ was an independent factor affecting tumor recurrence or uncontrolled, but it may be an independent factor for prognosis. For advanced cervical squamous cell carcinoma, setting the standard of tumor diameter as $6 \mathrm{~cm}$ may be an independent factor affecting prognosis, or whether the standard should be defined as other sizes needs to be further discussed. 


\section{Lymph node metastasis}

Lymph node metastasis of cervical cancer has been recognized as the main independent factor affecting the prognosis of patients with cervical cancer. For early cervical cancer, postoperative lymph node metastasis is regarded as the criterion of postoperative high-risk factor, and postoperative lymph node metastasis should be treated with concurrent chemoradiotherapy. A domestic study showed that lymph node metastasis was an independent risk factor for uncontrolled recurrence in patients with advanced cervical cancer after chemoradiotherapy[15]. Some studies showed that lymph node status [15] affected the OS and DFS, and the 3-year OS of patients with lymph node metastasis decreased from $92.8 \%$ to $81.7 \%$, and the survival time without distant metastasis decreased from $92.7 \%$ to $79.3 \%$ [6]. The same result had been obtained in foreign studies [5, 20, 21], Endo, D. et al. [19] showed that pelvic lymph node enlargement was an independent factor affecting prognosis, regardless of univariate analysis or multivariate analysis. Here, the latest FIG02018 staging of cervical cancer[22] divided patients with lymph node metastasis into IIIc stage, emphasizing the importance of lymph node metastasis in treatment choice and efficacy evaluation. Our univariate analysis showed a correlation between lymph node metastasis and prognosis, although multivariate analysis was not an independent prognostic factor. This may be the lack of a correct assessment of whether there was lymph node metastasis due to the economy, imaging technology, recognition of lymph node metastasis by medical staff and so on.

\section{Anemia}

The study of advanced II and III cervical cancer in Cancer Hospital Chinese Academy of Medical Sciences showed that the 5-year survival rate of patients with hemoglobin level below $80 \mathrm{~g} / \mathrm{L}$ before radiotherapy was about $20 \%$ lower than those with $80-100 \mathrm{~g} / \mathrm{L}$ and about $30 \%$ lower than those with $120 \mathrm{~g} / \mathrm{L}$ or above. A large number of other studies $[20,23]$ showed that anemia can significantly reduce the efficacy of chemoradiotherapy in advanced cervical cancer. It is considered that the level of hemoglobin lower than $110 \mathrm{~g} / \mathrm{L}$ was one of the factors of distant metastasis and an independent prognostic factor affecting prognosis, but it was still controversial as to which type of prognostic index hemoglobin was an independent prognostic factor. Teh, $\mathrm{J}$ et al.[18] analyzed the efficacy of concurrent chemoradiotherapy for locally advanced cervical cancer. Univariate and multivariate analysis showed that hemoglobin $<100 \mathrm{~g} / \mathrm{L}$ was an independent prognostic factor for OS, but not for DFS, Choi, Y. S. et al. [24] showed that hemoglobin $<100 \mathrm{~g} / \mathrm{L}$ was an independent prognostic factor for DFS in multivariate analysis. Our study showed that the average hemoglobin levels in chemoradiotherapy sensitive group and chemoradiotherapy resistant group were $109.4 \pm 19.9$ and $104.8 \pm 22.1$ respectively and the differences were statistically significant. It can be seen that the hemoglobin level affects chemoradiotherapy sensitivity.

Univariate analysis showed that hemoglobin was associated with OS and PFS, but hemoglobin was an independent prognostic factor for OS and PFS in multivariate analysis. Many scholars advocate that patients with cervical cancer should be actively corrected for anemia before radical radiotherapy in order to increase the sensitivity of tumor cells to radiotherapy and improve the effect of radiotherapy. However, 
which value of hemoglobin is the standard of $100 \mathrm{~g} / \mathrm{L}$ or $110 \mathrm{~g} / \mathrm{L}$ there is no uniform clinical standard of $\mathrm{HB}$, more clinical research data are required.

\section{NLR and PLR}

At present, most studies focus on the relationship between early cervical cancer and surgical outcome. Most studies suggested that the increase of NLR and PLR may indicate lymph node metastasis. Some studies believe that high NLR was associated with PFS and OS $[25,26]$, and there was no correlation between high NLR and PFS and OS [27, 28]. For PLR, it was also considered that high PLR has nothing to do with PFS and OS and was a prognostic factor [27]. Some studies have suggested that high PLR was associated with PFS and OS $[25,26,28]$. The conclusions of various studies were different and controversial.

There was also disagreement about the efficacy of NLR and PLR in the treatment of cervical cancer. Mizunuma, M. et, al [29] analyzed the efficacy of chemoradiotherapy in cervical squamous cell carcinoma, the results showed that the patients with high NLR before treatment had large tumor diameter, late stage, more lymph node metastasis and low CR rate after treatment. Univariate and multivariate analysis also showed that high NLR before treatment was a adverse prognostic factor for PFS and OS. Nakamura, K. et al. [30] analyzed the efficacy of second-line chemotherapy in patients with recurrent cervical cancer after chemoradiotherapy. There was no correlation between NLR and survival time before treatment. PLR was related to survival time in univariate and multivariate analysis. Further in-depth study, Mesut Kose et al. [31] analyzed that NLR and PLR were obviously increased before and after cervical cancer invasion, but correlation analysis showed that PLR was associated with invasion and NLR was not.

This study showed that both NLR and PLR are correlated with the sensitivity to chemoradiotherapy and the increase of NLR and PLR may be related to the resistance to chemoradiotherapy, but the result of ROC curve showed that AUC is about 0.5, which was not different from that of Another study[32]. It is of little value as a clinical diagnosis to predict the curative effect, and it is of more clinical value to add other indexes and establish a predictive model to provide the diagnosis rate of prognosis. NLR and PLR are prognostic factors of OS and PFS. There is a great divergence in the efficacy of NLR and PLR in the treatment of cervical cancer, and more clinical studies are needed.

\section{Total time of radiotherapy}

The total time of radiotherapy has always been an important factor in the prognosis of cervical cancer after radiotherapy. This study also showed whether the total time of radiotherapy was more than 8 weeks, and there was a correlation between the sensitive group and the resistant group. In the analysis of the effect on the prognosis, multiple factors showed that the total time of radiotherapy $>8$ weeks was an independent factor of OS and PFS in advanced cervical squamous cell carcinoma. 
However, the established total time of 6-8 weeks of radiotherapy was based on the results of simple radiotherapy. For advanced cervical cancer treated with concurrent chemoradiotherapy, the total time of radiotherapy may change, so the better time was also concerned. Atahan, I.L.et al. [5] showed that more than $6 \mathrm{w}$ was not a prognostic factor in cervical cancer LRFS, DMFS, DFS and OS, and prolonging the treatment time did not increase the mortality of distant failure and distant metastasis. According to Song et al. [33] , the total treatment time was 68 days (9-10 weeks), but the total radiotherapy time was less than 8 weeks, the 3 -year pelvic recurrence rate was $9 \%$ and $>8$ weeks was $20 \%$. It was of statistical significance. But the 3-year distant metastasis rate was $28 \%$ and $26 \%$ respectively, and the 3-year mortality rate was $26 \%$ and $29 \%$, respectively. There was no statistical difference. Multivariate analysis also showed the significance of pelvic recurrence, the overall survival and distant metastasis failure rate did not increase in advanced cervical squamous cell carcinoma, which may be related to chemotherapy. However, concurrent chemotherapy can not counteract the tumor cell proliferation caused by prolonged tumor time, so it was still recommended that the total radiotherapy time should be completed within 8 weeks to improve the local control rate.

\section{Conclusion}

To sum up, we conducted retrospective analysis of data of patients with advanced cervical squamous cell carcinoma treated with chemoradiotherapy collected in 9 years. Our result demonstrated a significant difference in 5-year survival rate between the chemoradiotherapy sensitive group and the resistant group. The main clinical factors affecting the chemoradiotherapy sensitivity were tumor stage, lymph node metastasis and the total time of radiotherapy. The analysis of prognostic factors of these patients showed that sensitivity to chemoradiotherapy, tumor diameter, NLR, PLR and total time of radiotherapy were independent prognostic factors of OS and PFS.

\section{Abbreviations}

OS: overall survival

PFS: progression free survival

NLR: neutrophil to lymphocyte ratio

PLR: platelet to lymphocyte ratio

PLR: platelet to lymphocyte ratio

LACC: locally advanced cervical cancer

FIGO: international federation of gynecology and obstetrics stage

ECOG: Eastern Cooperative Oncology Group 
CTV: clinical target volume

PTV: Planned target volum

OAR: organ at risk

RT: radiotherapy

HB: hemoglobin

LN: lymph node

TR: Total time of radiotherapy

CCRT: concurrent radiotherapy

AT: adjuvant chemotherapy

DDP: cisplatin

CBP: carboplatin

NDB: nedaplatin

TP: paclitaxel + cisplatin

PF: cisplatin + fluorouracil

DOX: docetaxel

TC: paclitaxel + carboplatin

2D: conventional radiotherapy

3D: appropriate radiotherapy

IMRT: intensity modulated radiotherapy

CCRTd: concurrent radiotherapy drugs

ATd: adjuvant chemotherapy drugs.

\section{Declarations}

Acknowledgments

Not applicable. 


\section{Funding}

This work was supported by National Natural Science Foundation of China (No.81672444, 81972643), Sichuan Science and Technology Project (2018JY0079). National Health and Family Planning Commission Public Welfare Research Project (No. 201402010)

\section{Authors' information}

\section{Affiliations}

Department of Oncology, Affiliated Hospital of Southwest Medical University, Luzhou, Sichuan, P.R. China Zhenhua Zhang, Jing Shen

Laboratory of Molecular Pharmacology, Department of Pharmacology, School of Pharmacy, Southwest Medical University, Luzhou, Sichuan, PR China

Qian Dai, Yueshui Zhao, Shixin Xiang, Mintao Xiao, Fukuan Du, Huijiao Ji, Parham Jabbarzadeh Kaboli, Xu Wu, Mingxing Li, Zhangang Xiao, Jing Shen

South Sichuan Institute of Translational Medicine, Luzhou, Sichuan, PR China

Yueshui Zhao, Mintao Xiao, Fukuan Du, Huijiao Ji, Parham Jabbarzadeh Kaboli, Xu Wu, Mingxing Li, Zhangang Xiao

Department of Oncology and Hematology, Hospital (T.C.M) Affiliated to Southwest Medical University, Luzhou, Sichuan, China

Qinglian Wen, Jing Li

Department of Gynecology, Affiliated Tumor Hospital of Guangxi Medical University and Key Laboratory of Early Prevention and Treatment of Regional High-incidence Tumors, Ministry of Education, Guangxi, China.

Li Li

\section{Contributions}

$Z Z$ designed the study, acquired the data. SX and MX analyzed the data. ZZ and QD wrote the manuscript. FD, HJ, PK, XW, ML, QW, JL and ZX provided critical review. YZ, JS and LL critically revised the manuscript. These authors contributed equally to this work. All authors read and approved the final manuscript.

\section{Corresponding author}

Correspondence to Jing Shen and Li Li. 


\section{Ethics declarations}

\section{Ethics approval and consent to participate}

The study was approved by the hospital ethical committee(Ethics Committee of Affiliated Hospital of Southwest Medical University)

\section{Consent for publication}

Not applicable.

\section{Availability of supporting data}

The data sets used and/ or analyzed during the current study are available from the corresponding author on reasonable request.

\section{Competing interests}

The authors declare that they have no competing interests.

\section{References}

1. Arbyn M, Weiderpass E, Bruni L, de Sanjosé S, Saraiya M, Ferlay J, Bray F: Estimates of incidence and mortality of cervical cancer in 2018: a worldwide analysis. The Lancet Global Health 2020, 8(2):e191e203.

2. Jiang X, Tang H, Chen T: Epidemiology of gynecologic cancers in China. J Gynecol Oncol 2018, 29(1):e7.

3. Todo Y, Watari H: Concurrent chemoradiotherapy for cervical cancer: background including evidencebased data, pitfalls of the data, limitation of treatment in certain groups. Chinese Journal of Cancer Research 2016, 28(2):221-227.

4. Teke F, Yoney A, Teke M, Adanas G, Urakci Z, Turkcu G, Eren B, Inal A, Unsal M: Evaluation of outcome and prognostic factors in 739 patients with uterine cervix carcinoma: a single institution experience. Contemp Oncol (Pozn) 2015, 19(2):130-136.

5. Atahan IL, Onal C, Ozyar E, Yiliz F, Selek U, Kose F: Long-term outcome and prognostic factors in patients with cervical carcinoma: a retrospective study. Int J Gynecol Cancer 2007, 17(4):833-842.

6. Li X, Wei L-C, Zhang Y, Zhao L-N, Li W-W, Ping L-J, Dang Y-Z, Hu J, Shi M: The Prognosis and Risk Stratification Based on Pelvic Lymph Node Characteristics in Patients With Locally Advanced Cervical Squamous Cell Carcinoma Treated With Concurrent Chemoradiotherapy. International Journal of Gynecologic Cancer 2016, 26(8):1472-1479.

7. An J-S, Huang M-N, Song Y-M, Li N, Wu L-Y, Zhan Q-M: A preliminary study of genes related to concomitant chemoradiotherapy resistance in advanced uterine cervical squamous cell carcinoma. Chin Med J 2013, 126(21):4109-4115. 
8. Chen CC, Wang L, Lin JC, Jan JS: The prognostic factors for locally advanced cervical cancer patients treated by intensity-modulated radiation therapy with concurrent chemotherapy. $J$ Formos Med Assoc 2015, 114(3):231-237.

9. Yamashita H, Nakagawa K, Tago M, Shiraishi K, Nakamura N, Ohtomo K: Treatment results and prognostic analysis of radical radiotherapy for locally advanced cancer of the uterine cervix. $\mathrm{Br} \mathrm{J}$ Radiol 2005, 78(933):821-826.

10. van der Horst J, Siebers AG, Bulten J, Massuger LF, de Kok IMCM: Increasing incidence of invasive and in situ cervical adenocarcinoma in the Netherlands during 2004-2013. Cancer Medicine 2017, 6(2):416-423.

11. Galic V, Herzog TJ, Lewin SN, Neugut Al, Burke WM, Lu YS, Hershman DL, Wright JD: Prognostic significance of adenocarcinoma histology in women with cervical cancer. Gynecol Oncol 2012, 125(2):287-291.

12. Ruey-Jien Chen『Yu-Hung Lin C-AC, Su-Cheng Huang, Song-Nan Chow, and Chang-Yao Hsieh: Influence of Histologic Type and Age on Survival Rates for Invasive Cervical Carcinoma in Taiwan. Gynecologic Oncology 1998, 73:184 -190.

13. Liu YM, Ni LQ, Wang SS, Lv QL, Chen WJ, Ying SP: Outcome and prognostic factors in cervical cancer patients treated with surgery and concurrent chemoradiotherapy: a retrospective study. World J Surg Oncol 2018, 16(1):18.

14. Kastritis E, Bamias A, Bozas G, Koutsoukou V, Voulgaris Z, Vlahos G, Rodolakis A, Gika D, Papadimitriou C, Dimopoulos MA: The impact of age in the outcome of patients with advanced or recurrent cervical cancer after platinum-based chemotherapy. Gynecol Oncol 2007, 104(2):372-376.

15. Binbin T, Lingying W, Manni H, Jusheng A, Ning L: [Outcomes and prognostic factors of advanced squamous cervical cancer after concurrent chemoradiotherapy]. Zhonghua Fu Chan Ke Za Zhi 2014, 49(5):348-354.

16. Kim TE, Park BJ, Kwack HS, Kwon JY, Kim JH, Yoon SC: Outcomes and prognostic factors of cervical cancer after concurrent chemoradiation. J Obstet Gynaecol Res 2012, 38(11):1315-1320.

17. Horn LC, Fischer U, Raptis G, Bilek K, Hentschel B: Tumor size is of prognostic value in surgically treated FIGO stage II cervical cancer. Gynecol Oncol 2007, 107(2):310-315.

18. Teh J, Yap SP, Tham I, Sethi VK, Chua EJ, Yeo R, Ho TH, Tay EH, Chia YN, Soh LT et al: Concurrent Chemoradiotherapy Incorporating High-Dose Rate Brachytherapy for Locally Advanced Cervical Carcinoma. International Journal of Gynecological Cancer 2010, 20(3):428-433.

19. Endo D, Todo Y, Okamoto K, Minobe S, Kato H, Nishiyama N: Prognostic factors for patients with cervical cancer treated with concurrent chemoradiotherapy: a retrospective analysis in a Japanese cohort. Journal of Gynecologic Oncology 2015, 26(1).

20. Parker K, Gallop-Evans E, Hanna L, Adams M: Five years' experience treating locally advanced cervical cancer with concurrent chemoradiotherapy and high-dose-rate brachytherapy: results from a single institution. Int J Radiat Oncol Biol Phys 2009, 74(1):140-146. 
21. Lim A, Sia S: Outcomes of chemoradiotherapy in cervical cancer-the Western Australian experience. Int J Radiat Oncol Biol Phys 2012, 82(4):1431-1438.

22. Bhatla N, Aoki D, Sharma DN, Sankaranarayanan R: Cancer of the cervix uteri. Int J Gynaecol Obstet 2018, 143 Suppl 2:22-36.

23. Ma R, Zhang H, Zou L, Qu Y: Outcomes and prognostic factors of distant metastasis in patients with advanced cervical squamous cell carcinoma treated with concurrent chemoradiotherapy. Zhonghua Fu Chan Ke Za Zhi 2015, 50(2):125-130.

24. Choi YS, Yi CM, Sin JI, Ye GW, Shin IH, Lee TS: Impact of hemoglobin on survival of cervical carcinoma patients treated with concurrent chemoradiotherapy is dependent on lymph node metastasis findings by magnetic resonance imaging. Int J Gynecol Cancer 2006, 16(5):1846-1854.

25. Zhang Y, Wang L, Liu Y, Wang S, Shang P, Gao Y, Chen X: Preoperative neutrophil-lymphocyte ratio before platelet-lymphocyte ratio predicts clinical outcome in patients with cervical cancer treated with initial radical surgery. Int J Gynecol Cancer 2014, 24(7):1319-1325.

26. Lee Y-Y, Choi CH, Kim H-J, Kim T-J, Lee J-W, Lee J-H, Bae D-S, Kim B-G: Pretreatment neutrophil:lymphocyte ratio as a prognostic factor in cervical carcinoma. Anticancer Res 2012, 32(4):1555-1561.

27. Zhu M, Feng M, He F, Han B, Ma K, Zeng X, Liu Z, Liu X, Li J, Cao H et al: Pretreatment neutrophillymphocyte and platelet-lymphocyte ratio predict clinical outcome and prognosis for cervical Cancer. Clin Chim Acta 2018, 483:296-302.

28. Wang D, Wu M, Feng F-z, Huang H-f, Yang J-x, Shen K, Xiang Y: Pretreatment neutrophil-tolymphocyte and platelet-to-lymphocyte ratios do not predict survival in patients with cervical cancer treated with neoadjuvant chemotherapy and radical hysterectomy. Chin Med J 2013, 126(8):14641468.

29. Mizunuma M, Yokoyama Y, Futagami M, Aoki M, Takai Y, Mizunuma H: The pretreatment neutrophilto-lymphocyte ratio predicts therapeutic response to radiation therapy and concurrent chemoradiation therapy in uterine cervical cancer. Int J Clin Oncol 2015, 20(5):989-996.

30. Nakamura K, Nishida T, Haruma T, Haraga J, Omichi C, Ogawa C, Kusumoto T, Seki N, Masuyama H, Hiramatsu Y: Pretreatment platelet-lymphocyte ratio is an independent predictor of cervical cancer recurrence following concurrent chemoradiation therapy. Mol Clin Oncol 2015, 3(5):1001-1006.

31. Kose M, Celik F, Kose SK, Arioz DT, Yilmazer M: Could the platelet-to-lymphocyte ratio be a novel marker for predicting invasiveness of cervical pathologies? Asian Pac J Cancer Prev 2015, 16(3):923926.

32. Zheng R-R, Huang M, Jin C, Wang H-C, Yu J-T, Zeng L-C, Zheng F-Y, Lin F: Cervical cancer systemic inflammation score: a novel predictor of prognosis. Oncotarget 2016, 7(12):15230-15242.

33. Song S, Rudra S, Hasselle MD, Dorn PL, Mell LK, Mundt AJ, Yamada SD, Lee NK, Hasan Y: The effect of treatment time in locally advanced cervical cancer in the era of concurrent chemoradiotherapy. Cancer 2013, 119(2):325-331. 


\section{Tables}

Table 1. General characteristics of patients 


\begin{tabular}{|c|c|c|c|}
\hline Clinical features & RT sensitive $(\mathrm{N}=738)$ & $\mathrm{RT}$ resistant $(\mathrm{N}=227)$ & P-value \\
\hline Age(years) & $53.09(9.50)$ & $52.40(10.06)$ & 0.438 \\
\hline Status(example, \%) & & & $<0.001$ \\
\hline alive & $574(77.81)$ & 73 (32.24) & \\
\hline death & $164(22.23)$ & $154(67.82)$ & \\
\hline OS (months) & $49.62(28.43)$ & $27.13(28.34)$ & $<0.001$ \\
\hline PFS (months) & $48.49(28.3)$ & $31.86(29.30)$ & $<0.001$ \\
\hline Stage (example, \%) & & & 0.025 \\
\hline IIb-IIla & $180(24.4)$ & $39(17.3)$ & \\
\hline$\geq 111 \mathrm{~b}$ & $557(75.6)$ & $187(82.7)$ & \\
\hline Diameter (example, \%) & & & 0.298 \\
\hline$<=4 \mathrm{~cm}$ & $227(37.9)$ & 63 (33.7) & \\
\hline$>4 \mathrm{~cm}$ & $372(62.1)$ & $124(66.3)$ & \\
\hline HB (mean (SD)) & $109.4(19.9)$ & $104.8(22.1)$ & 0.004 \\
\hline NLR (mean (SD)) & $3.0(1.9)$ & $3.4(2.4)$ & 0.019 \\
\hline PLR (mean (SD)) & $182.9(97.1)$ & 196.7 (108.9) & 0.158 \\
\hline LN (example, \%) & & & $<0.001$ \\
\hline no metastasis & $423(66.0)$ & $100(49.8)$ & \\
\hline metastasis & $218(34.0)$ & $101(50.2)$ & \\
\hline TR (\%) & & & 0.011 \\
\hline$<=8$ weeks & $295(40.1)$ & $69(30.7)$ & \\
\hline > 8 weeks & 441 (59.9) & $156(69.3)$ & \\
\hline CCRT (weeks) & $3.6(1.8)$ & $3.4(2.0)$ & 0.253 \\
\hline AT (weeks) & $1.5(1.6)$ & $1.5(1.5)$ & 0.659 \\
\hline Hospital & & & 0.263 \\
\hline GuangXi & $582(79.0)$ & $187(82.4)$ & \\
\hline XiNan & $155(21.0)$ & $40(17.6)$ & \\
\hline
\end{tabular}

Note: RT: radiotherapy; OS: overall survival; PFS: progression free survival; HB: hemoglobin; NLR: neutrophil to lymphocyte ratio; PLR: platelet to lymphocyte ratio; LN: lymph node; TR: Total time of 
radiotherapy; CCRT: concurrent radiotherapy; AT: adjuvant chemotherapy.

Table 2. Analysis of clinical factors affecting the sensitivity of chemoradiotherapy 


\begin{tabular}{|c|c|c|c|c|c|c|}
\hline \multirow{2}{*}{$\begin{array}{l}\text { Clinical } \\
\text { factors }\end{array}$} & \multirow{2}{*}{$\begin{array}{l}\text { RT sensitive } \\
\text { (example,\%) }\end{array}$} & \multirow{2}{*}{$\begin{array}{l}\text { RT resistant } \\
\text { (example,\%) }\end{array}$} & \multicolumn{2}{|c|}{ Univariate analysis } & \multicolumn{2}{|c|}{ Multivariate analysis } \\
\hline & & & $\begin{array}{l}\text { OR }(95 \% \\
\mathrm{Cl})\end{array}$ & $\begin{array}{l}\mathrm{P}- \\
\text { value }\end{array}$ & OR $(95 \% \mathrm{Cl})$ & $\begin{array}{l}\mathrm{P} \text { - } \\
\text { value }\end{array}$ \\
\hline \multicolumn{7}{|l|}{ Age (years) } \\
\hline $40-60$ & $542(73.4)$ & 163 (71.8) & & & & \\
\hline$<40$ & $43(5.8)$ & $18(7.9)$ & $\begin{array}{l}1.39(0.76- \\
2.44)\end{array}$ & 0.262 & $\begin{array}{l}0.87(0.28- \\
2.39)\end{array}$ & 0.795 \\
\hline$>60$ & 153 (20.7) & $46(20.3)$ & $\begin{array}{l}1.00(0.68- \\
1.44)\end{array}$ & 0.999 & $\begin{array}{l}1.06(0.41- \\
2.51)\end{array}$ & 0.896 \\
\hline \multicolumn{7}{|l|}{ Stage } \\
\hline IIb-IIla & $180(24.4)$ & 39 (17.3) & ref & & ref & \\
\hline$\geq I I I b$ & $557(75.6)$ & 187 (82.7) & $\begin{array}{l}11.55(1.07- \\
2.30)\end{array}$ & 0.025 & $\begin{array}{l}0.99(0.53- \\
1.88)\end{array}$ & 0.972 \\
\hline \multicolumn{7}{|l|}{$\begin{array}{l}\text { Tumor } \\
\text { diameter }\end{array}$} \\
\hline$<=4 \mathrm{~cm}$ & 227 (37.9) & 63 (33.7) & ref & & ref & \\
\hline$>4 \mathrm{~cm}$ & $372(62.1)$ & $124(66.3)$ & $\begin{array}{l}1.20(0.85- \\
1.70)\end{array}$ & 0.298 & $\begin{array}{l}1.07(0.62- \\
1.87)\end{array}$ & 0.820 \\
\hline \multicolumn{7}{|l|}{ Lymph node } \\
\hline no metastasis & $423(66.0)$ & $100(49.8)$ & ref & & ref & \\
\hline metastasis & $218(34.0)$ & $101(50.2)$ & $\begin{array}{l}1.96(1.42- \\
2.70)\end{array}$ & $<0.001$ & $\begin{array}{l}1.45(0.85- \\
2.47)\end{array}$ & 0.169 \\
\hline \multicolumn{7}{|l|}{ TR (months) } \\
\hline$<=8$ & $295(40.1)$ & $69(30.7)$ & ref & & ref & \\
\hline$>8$ & $441(59.9)$ & $156(69.3)$ & $\begin{array}{l}1.51(1.10- \\
2.09)\end{array}$ & 0.011 & $\begin{array}{l}2.11(1.16- \\
3.96)\end{array}$ & 0.012 \\
\hline \multicolumn{7}{|l|}{ CCRT } \\
\hline no & $85(11.5)$ & $39(17.2)$ & & & & \\
\hline yes & $653(88.5)$ & 188 (82.8) & $\begin{array}{l}0.63(0.42- \\
0.96)\end{array}$ & 0.027 & $\begin{array}{l}1.59(0.24- \\
2.96)\end{array}$ & 0.993 \\
\hline \multicolumn{7}{|l|}{ AT } \\
\hline no & $324(43.9)$ & 89 (39.2) & & & & \\
\hline yes & $414(56.1)$ & $138(60.8)$ & $\begin{array}{l}1.21(0.90- \\
1.65)\end{array}$ & 0.212 & $\begin{array}{l}1.544(0.12- \\
2.37)\end{array}$ & 0.993 \\
\hline
\end{tabular}




\begin{tabular}{|c|c|c|c|c|c|c|}
\hline \multirow{2}{*}{$\begin{array}{l}\text { Clinical } \\
\text { factors }\end{array}$} & \multirow{2}{*}{$\begin{array}{l}\text { RT sensitive } \\
\text { (example,\%) }\end{array}$} & \multirow{2}{*}{$\begin{array}{l}\text { RT resistant } \\
\text { (example,\%) }\end{array}$} & \multicolumn{2}{|c|}{ Univariate analysis } & \multicolumn{2}{|c|}{ Multivariate analysis } \\
\hline & & & $\begin{array}{l}\text { OR }(95 \% \\
\mathrm{Cl})\end{array}$ & $\begin{array}{l}\mathrm{P} \text { - } \\
\text { value }\end{array}$ & OR $(95 \% \mathrm{Cl})$ & $\begin{array}{l}\mathrm{P}- \\
\text { value }\end{array}$ \\
\hline \multicolumn{7}{|l|}{ CCRTd } \\
\hline DDP & $424(65.3)$ & 116 (61.7) & & & & \\
\hline CBP & $31(4.8)$ & $15(8.0)$ & $\begin{array}{l}1.77(0.90- \\
3.34,)\end{array}$ & 0.085 & $\begin{array}{l}2.95(2.10- \\
4.17)\end{array}$ & 0.081 \\
\hline NDB & $162(25.0)$ & $53(28.2)$ & $\begin{array}{l}1.20(0.82- \\
1.73)\end{array}$ & 0.346 & $\begin{array}{l}1.03(0.52- \\
2.01)\end{array}$ & 0.931 \\
\hline others & 32 (4.9) & $4(2.1)$ & $\begin{array}{l}0.46(0.13- \\
1.18)\end{array}$ & 0.147 & $\begin{array}{l}0.28(0.04- \\
1.10)\end{array}$ & 0.109 \\
\hline \multicolumn{7}{|l|}{ ATd } \\
\hline TP & 127 (31.0) & $35(26.3)$ & $\begin{array}{l}0.99(0.51- \\
1.89)\end{array}$ & 0.988 & $\begin{array}{l}1.42 \\
(0.57 .-3.44)\end{array}$ & 0.444 \\
\hline PF & $62(15.1)$ & $17(12.8)$ & $\begin{array}{l}1.21(0.52- \\
2.65)\end{array}$ & 0.644 & $\begin{array}{l}1.01(0.31- \\
2.97)\end{array}$ & 0.985 \\
\hline DOX+CBP & $30(7.3)$ & $10(7.5)$ & $\begin{array}{l}1.35(0.63- \\
2.78)\end{array}$ & 0.428 & $\begin{array}{l}1.04(0.36- \\
2.83)\end{array}$ & 0.936 \\
\hline $\mathrm{DOX}+\mathrm{NDB}$ & 35 (8.5) & $13(9.8)$ & $\begin{array}{l}1.21(0.58- \\
2.43)\end{array}$ & 0.600 & $\begin{array}{l}1.33(0.49- \\
3.46)\end{array}$ & 0.562 \\
\hline $\mathrm{DOX}+\mathrm{OXA}$ & $42(10.2)$ & $14(10.5)$ & $\begin{array}{l}1.40(0.70- \\
2.72)\end{array}$ & 0.325 & $\begin{array}{l}2.01(0.83- \\
4.76)\end{array}$ & 0.114 \\
\hline TC & $40(9.8)$ & $14(10.5)$ & $\begin{array}{l}1.27(0.61- \\
2.56)\end{array}$ & 0.512 & $\begin{array}{l}0.38(0.05- \\
1.61)\end{array}$ & 0.241 \\
\hline others & $30(7.3)$ & $13(9.8)$ & $\begin{array}{l}1.57(0.73- \\
3.29)\end{array}$ & 0.237 & $\begin{array}{l}2.59(0.93- \\
7.10)\end{array}$ & 0.065 \\
\hline \multicolumn{7}{|l|}{ RT } \\
\hline $2 \mathrm{D}$ & $343(47.3)$ & $99(44.2)$ & - & & & \\
\hline 3D & $92(12.7)$ & $26(11.6)$ & $\begin{array}{l}0.98(0.59- \\
1.58)\end{array}$ & 0.933 & $\begin{array}{l}1.19(0.51- \\
2.70)\end{array}$ & 0.678 \\
\hline IMRT & $290(40.0)$ & $99(44.2)$ & $\begin{array}{l}1.18(0.86- \\
1.63)\end{array}$ & 0.303 & $\begin{array}{l}1.54(0.77- \\
3.11)\end{array}$ & 0.226 \\
\hline
\end{tabular}

Note: DDP: cisplatin; CBP: carboplatin; NDB: nedaplatin; TP: paclitaxel + cisplatin; PF: cisplatin + fluorouracil; DOX: docetaxel; TC: paclitaxel + carboplatin; 2D: conventional radiotherapy; 3D: appropriate radiotherapy; IMRT: intensity modulated radiotherapy; CCRTd: concurrent radiotherapy drugs; ATd: adjuvant chemotherapy drugs. 
Table 3. Analysis of clinical factors affecting chemoradiotherapy OS 


\begin{tabular}{|c|c|c|c|c|c|}
\hline \multirow{2}{*}{$\begin{array}{l}\text { Clinical } \\
\text { factors }\end{array}$} & \multirow{2}{*}{$\begin{array}{l}\text { Number of } \\
\text { cases } \\
\text { (example) }\end{array}$} & \multicolumn{2}{|l|}{ Univariate analysis } & \multicolumn{2}{|l|}{ Multivariate analysis } \\
\hline & & HR $(95 \% \mathrm{Cl})$ & $P$ & HR $(95 \% \mathrm{Cl})$ & $P$ \\
\hline Grouping & & & $<0.001$ & & $<0.001$ \\
\hline RT sensitive & 738 & ref & & ref & \\
\hline RT resistant & 227 & $4.59(3.68-5.73)$ & & $6.75(5.02-9.08)$ & \\
\hline Age (years) & 965 & $1.00(0.99-1.01)$ & 0.802 & $1.01(0.99-1.03)$ & 0.274 \\
\hline $40-60$ & 705 & ref & & ref & \\
\hline$<40$ & 61 & $\begin{array}{l}0.8035(0.5451- \\
1.211)\end{array}$ & 0.3166 & $0.641(0.276-1.489)$ & 0.301 \\
\hline$>60$ & 199 & $\begin{array}{l}0.9557(0.7201- \\
1.268)\end{array}$ & 0.7544 & $0.799(0.529-1.204)$ & 0.283 \\
\hline Stage & & & 0.393 & & 0.0542 \\
\hline IIb-IIla & 219 & ref & & ref & \\
\hline$\geq I I I b$ & 746 & $1.14(0.85-1.53)$ & & $0.67(0.47-1.03)$ & \\
\hline Diameter & & & 0.019 & & 0.005 \\
\hline$<=4 \mathrm{~cm}$ & 290 & ref & & ref & \\
\hline$>4 \mathrm{~cm}$ & 496 & $1.38(1.06-1.01)$ & & $1.59(1.15-2.20)$ & \\
\hline \multicolumn{6}{|l|}{ CCRT } \\
\hline no & 124 & ref & & ref & \\
\hline yes & 841 & $\begin{array}{l}0.8661(0.6798 \text { - } \\
1.079)\end{array}$ & 0.1971 & $0.164(0.022-1.243)$ & 0.08 \\
\hline \multicolumn{6}{|l|}{ AT } \\
\hline no & 413 & ref & & ref & \\
\hline yes & 552 & $\begin{array}{l}0.9972(0.7973- \\
1.247)\end{array}$ & 0.9801 & $0.418(0.098-1.780)$ & 0.238 \\
\hline \multicolumn{6}{|l|}{ CCRTd } \\
\hline DDP & 540 & & & & \\
\hline CBP & 46 & $1.059(0.6487-1.742)$ & 0.812 & $0.124(0.014-1.100)$ & 0.061 \\
\hline NDB & 215 & $\begin{array}{l}1.201(0.8578- \\
1.812)\end{array}$ & 0.2764 & $1.254(0.914-1.721)$ & 0.161 \\
\hline others & 36 & $0.733(0.4436-1.278)$ & 0.3036 & $0.150(0.016-1.363)$ & 0.092 \\
\hline
\end{tabular}




\begin{tabular}{|c|c|c|c|c|c|}
\hline \multirow{2}{*}{$\begin{array}{l}\text { Clinical } \\
\text { factors }\end{array}$} & \multirow{2}{*}{$\begin{array}{l}\text { Number of } \\
\text { cases } \\
\text { (example) }\end{array}$} & \multicolumn{2}{|l|}{ Univariate analysis } & \multicolumn{2}{|l|}{ Multivariate analysis } \\
\hline & & $\mathrm{HR}(95 \% \mathrm{Cl})$ & $P$ & HR $(95 \% \mathrm{Cl})$ & $P$ \\
\hline \multicolumn{6}{|l|}{ ATD } \\
\hline TP & 162 & $1.242(0.9305-1.734)$ & 0.1386 & & \\
\hline PF & 79 & $\begin{array}{l}0.7774(0.5642- \\
1.083)\end{array}$ & 0.1505 & $0.790(0.383-1.630)$ & 0.524 \\
\hline $\mathrm{DOX}+\mathrm{CBP}$ & 40 & $1.392(0.6847-3.247)$ & 0.3221 & $1.010(0.583-1.748)$ & 0.973 \\
\hline DOX+NDB & 48 & $1.689(0.9323-4.367)$ & 0.0806 & $1.458(0.820-2.591)$ & 0.199 \\
\hline DOX+OXA & 56 & $1.37(0.6765-3.171)$ & 0.3433 & $1.057(0.745-1.498)$ & 0.757 \\
\hline TC & 54 & $\begin{array}{l}0.9172(0.5887- \\
1.429)\end{array}$ & 0.7074 & $0.679(0.511-0.902)$ & 0.008 \\
\hline others & 104 & $1.039(0.7429-1.456)$ & 0.8211 & $0.927(0.821-1.047)$ & 0.222 \\
\hline \multicolumn{6}{|l|}{ RT } \\
\hline $2 \mathrm{D}$ & 442 & & & & \\
\hline $3 \mathrm{D}$ & 118 & $1.189(0.8300-1.767)$ & 0.33 & $0.844(0.441-1.616)$ & 0.608 \\
\hline IMRT & 389 & $1.275(1.030-1.817)$ & 0.0495 & $1.054(0.790-1.406)$ & 0.72 \\
\hline HB & 965 & $0.99(0.99-1.00)$ & 0.012 & $1.01(1.00-1.01)$ & 0.14 \\
\hline NLR & 965 & $1.08(1.03-1.12)$ & $<0.001$ & $1.08(1.01-1.15)$ & 0.028 \\
\hline PLR & 965 & $1.00(1.00-1.00)$ & $<0.001$ & $\begin{array}{l}1.002 \\
(1.000-1.004)\end{array}$ & 0.005 \\
\hline Lymph node & & & $<0.001$ & & 0.127 \\
\hline $\begin{array}{l}\text { no } \\
\text { metastasis }\end{array}$ & 523 & ref & & ref & \\
\hline metastasis & 312 & $1.71(1.33-2.20)$ & & $1.26(0.94-1.71)$ & \\
\hline TR(months) & & & 0.37 & & 0.012 \\
\hline$<=8$ & 367 & ref & & ref & \\
\hline$>8$ & 599 & $1.13(0.87-1.46)$ & & $1.53(1.10-2.14)$ & \\
\hline CCRT (weeks) & 965 & $0.95(0.89-1.00)$ & 0.07 & $0.94(0.87-1.01)$ & 0.072 \\
\hline AT (weeks) & 965 & $0.99(0.92-1.06)$ & 0.704 & $1.02(0.93-1.13)$ & 0.062 \\
\hline Hospital & & & 0.634 & & 0.281 \\
\hline
\end{tabular}




\begin{tabular}{|llllll|}
\hline $\begin{array}{l}\text { Clinical } \\
\text { factors }\end{array}$ & $\begin{array}{l}\text { Number of } \\
\text { cases }\end{array}$ & Univariate analysis & & \multicolumn{2}{l|}{ Multivariate analysis } \\
\cline { 2 - 4 } & (example) & HR $(95 \% \mathrm{Cl})$ & P & HR $(95 \% \mathrm{Cl})$ & $\mathrm{P}$ \\
\hline GuangXi & 769 & ref & ref & \\
\hline XiNan & 195 & $1.07(0.82-1.39)$ & & $1.20(0.86-1.66)$ & \\
\hline
\end{tabular}

Table 4. Analysis of clinical factors affecting chemoradiotherapy PFS 


\begin{tabular}{|c|c|c|c|c|c|}
\hline $\begin{array}{l}\text { Clinical } \\
\text { factors }\end{array}$ & $\begin{array}{l}\text { Number of } \\
\text { cases }\end{array}$ & univariate analysis & & Multivariate analysi & \\
\hline (example) & HR $(95 \% \mathrm{Cl})$ & $P$ & $\begin{array}{l}\mathrm{HR}(95 \% \\
\mathrm{Cl})\end{array}$ & $P$ & \\
\hline Grouping & & & $<0.001$ & & $<0.001$ \\
\hline RT sensitive & 738 & ref & & ref & \\
\hline RT resistant & 227 & $5.04(4.03-6.29)$ & & $7.18(5.35-9.64)$ & \\
\hline Age & 965 & $1.00(0.99-1.01)$ & 0.92 & $1.01(0.99-1.03)$ & 0.0278 \\
\hline $40-60$ & 705 & ref & & ref & \\
\hline$<40$ & 61 & $0.91(0.5981-1.388)$ & 0.6687 & $\begin{array}{l}0.647(0.275- \\
1.521)\end{array}$ & 0.318 \\
\hline$>60$ & 199 & $\begin{array}{l}0.9224(0.6926- \\
1.230)\end{array}$ & 0.5871 & $\begin{array}{l}0.820(0.514- \\
1.231)\end{array}$ & 0.338 \\
\hline Stage & & & 0.235 & & 0.068 \\
\hline \|lb-IIIa & 219 & ref & & ref & \\
\hline$\geq \mathrm{Illb}$ & 746 & $1.20(0.893-1.61)$ & & $0.70(0.48-1.03)$ & \\
\hline Diameter & & & 0.039 & & 0.1063 \\
\hline$<=4 \mathrm{~cm}$ & 290 & ref & & ref & \\
\hline$>4 \mathrm{~cm}$ & 496 & $1.33(1.01-1.74)$ & & $1.52(1.10-2.10)$ & \\
\hline \multicolumn{6}{|l|}{ CCRT } \\
\hline no & 124 & & & & \\
\hline yes & 841 & $\begin{array}{l}0.6785(0.4435- \\
0.9026)\end{array}$ & 0.0123 & $\begin{array}{l}0.168(0.022- \\
1.276)\end{array}$ & 0.085 \\
\hline \multicolumn{6}{|l|}{ AT } \\
\hline no & 413 & & & & \\
\hline yes & 552 & $\begin{array}{l}1.012(0.8055- \\
1.271)\end{array}$ & 0.9195 & $\begin{array}{l}0.422(0.098- \\
1.807)\end{array}$ & 0.245 \\
\hline \multicolumn{6}{|l|}{ CCRTd } \\
\hline DDP & 540 & & & & \\
\hline CBP & 46 & $1.03(0.6246-1.704)$ & 0.9046 & $\begin{array}{l}0.590(0.254- \\
1.371)\end{array}$ & 0.22 \\
\hline NDB & 215 & $\begin{array}{l}1.003(0.6939- \\
1.452)\end{array}$ & 0.9848 & $\begin{array}{l}1.133(0.829- \\
1.548)\end{array}$ & 0.435 \\
\hline
\end{tabular}




\begin{tabular}{|c|c|c|c|c|c|}
\hline \multirow{2}{*}{$\begin{array}{l}\text { Clinical } \\
\text { factors }\end{array}$} & \multirow{2}{*}{$\begin{array}{l}\text { Number of } \\
\text { cases }\end{array}$} & \multicolumn{2}{|l|}{ univariate analysis } & \multicolumn{2}{|c|}{ Multivariate analysis } \\
\hline & & $\begin{array}{l}0.7003(0.4311- \\
1.219)\end{array}$ & 0.2365 & $\begin{array}{l}1.070(0.796- \\
1.439)\end{array}$ & 0.654 \\
\hline \multicolumn{6}{|l|}{ ATD_cat } \\
\hline TP & 162 & & & & \\
\hline PF & 79 & $\begin{array}{l}0.7032(0.4480- \\
1.016)\end{array}$ & 0.0782 & $\begin{array}{l}0.885(0.439- \\
1.782)\end{array}$ & 0.732 \\
\hline $\mathrm{DOX}+\mathrm{CBP}$ & 40 & $\begin{array}{l}1.012(0.4815 \text { - } \\
2.129)\end{array}$ & 0.9743 & $\begin{array}{l}1.120(0.653- \\
1.919)\end{array}$ & 0.681 \\
\hline DOX+NDB & 48 & $\begin{array}{l}1.216(0.6094- \\
2.579)\end{array}$ & 0.5532 & $\begin{array}{l}1.149(0.793- \\
1.664)\end{array}$ & 0.463 \\
\hline DOX+OXA & 56 & $\begin{array}{l}1.011(0.4813- \\
2.127)\end{array}$ & 0.9764 & $\begin{array}{l}1.138(0.883- \\
1.467)\end{array}$ & 0.318 \\
\hline TC & 54 & $\begin{array}{l}0.7051(0.4360- \\
1.142)\end{array}$ & 0.1703 & $\begin{array}{l}0.779(0.648- \\
0.936)\end{array}$ & 0.008 \\
\hline others & 104 & $\begin{array}{l}0.8084(0.5334 \text { - } \\
1.185)\end{array}$ & 0.2806 & $\begin{array}{l}0.936(0.841- \\
1.039)\end{array}$ & 0.209 \\
\hline \multicolumn{6}{|l|}{ RT } \\
\hline $2 \mathrm{D}$ & 442 & & & & \\
\hline $3 \mathrm{D}$ & 118 & $\begin{array}{l}1.112(0.7720- \\
1.630)\end{array}$ & 0.5551 & $\begin{array}{l}0.807(0.417- \\
1.562)\end{array}$ & 0.525 \\
\hline IMRT & 389 & $\begin{array}{l}1.017(0.7676- \\
1.358)\end{array}$ & 0.8973 & $\begin{array}{l}0.990(0.744- \\
1.317)\end{array}$ & 0.945 \\
\hline $\mathrm{HB}$ & 965 & $0.99(0.99-1.00)$ & 0.011 & $1.01(1.00-1.01)$ & 0.205 \\
\hline NLR & 965 & $1.07(1.023-1.12)$ & 0.001 & $1.07(1.00-1.15)$ & 0.036 \\
\hline PLR & 965 & $\begin{array}{l}1.002(1.002- \\
1.003)\end{array}$ & 0.001 & $\begin{array}{l}1.003(1.002- \\
1.004)\end{array}$ & 0.009 \\
\hline Lymph node & & & $<0.001$ & & 0.096 \\
\hline $\begin{array}{l}\text { no } \\
\text { metastasis }\end{array}$ & 523 & ref & & ref & \\
\hline metastasis & 312 & $1.69(1.32-2.17)$ & & $1.29(0.96-1.74)$ & \\
\hline TR (weeks) & & & 0.162 & & 0.011 \\
\hline$<=8$ & 367 & ref & & ref & \\
\hline$>8$ & 599 & $1.20(0.93-1.56)$ & & $1.54(1.11-2.16)$ & \\
\hline
\end{tabular}




\begin{tabular}{|llllll|}
\hline $\begin{array}{l}\text { Clinical } \\
\text { factors }\end{array}$ & $\begin{array}{l}\text { Number of } \\
\text { cases }\end{array}$ & univariate analysis & & \multicolumn{2}{l|}{ Multivariate analysis } \\
\hline $\begin{array}{l}\text { CCRT } \\
\text { (weeks) }\end{array}$ & 965 & $0.96(0.90-1.01)$ & 0.144 & $0.95(0.88-1.01)$ & 0.118 \\
\hline AT (weeks) & 965 & $0.99(0.92-1.06)$ & 0.697 & $1.04(0.95-1.15)$ & 0.361 \\
\hline Hospital & 738 & & 0.824 & & 0.212 \\
\hline GuangXi & 227 & ref & & ref & \\
\hline XiNan & 195 & $1.03(0.79-1.35)$ & & $1.23(0.89-1.71)$ & \\
\hline
\end{tabular}

\section{Figures}


A

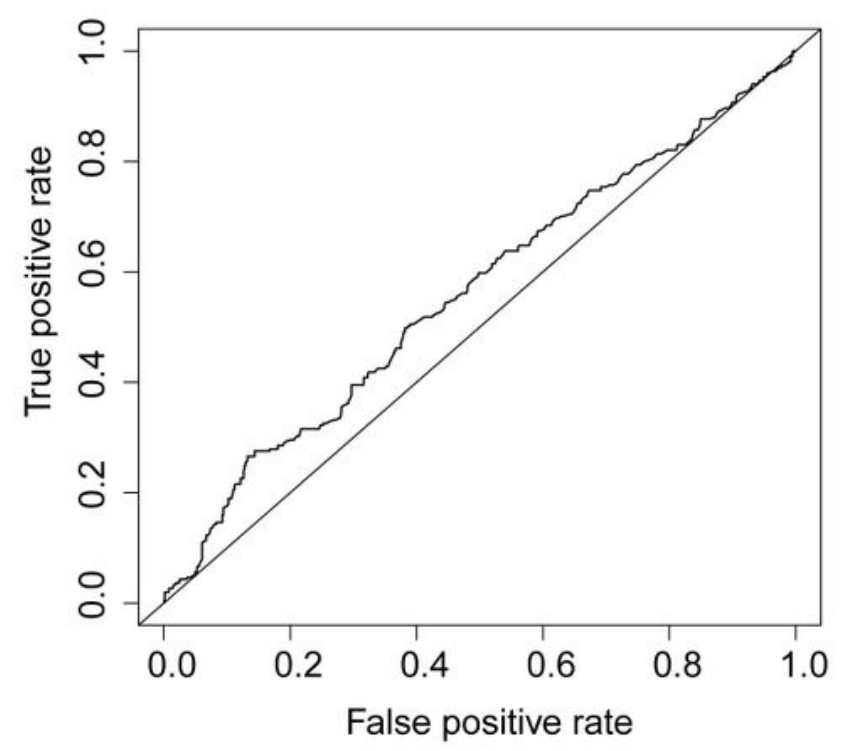

$\mathrm{C}$
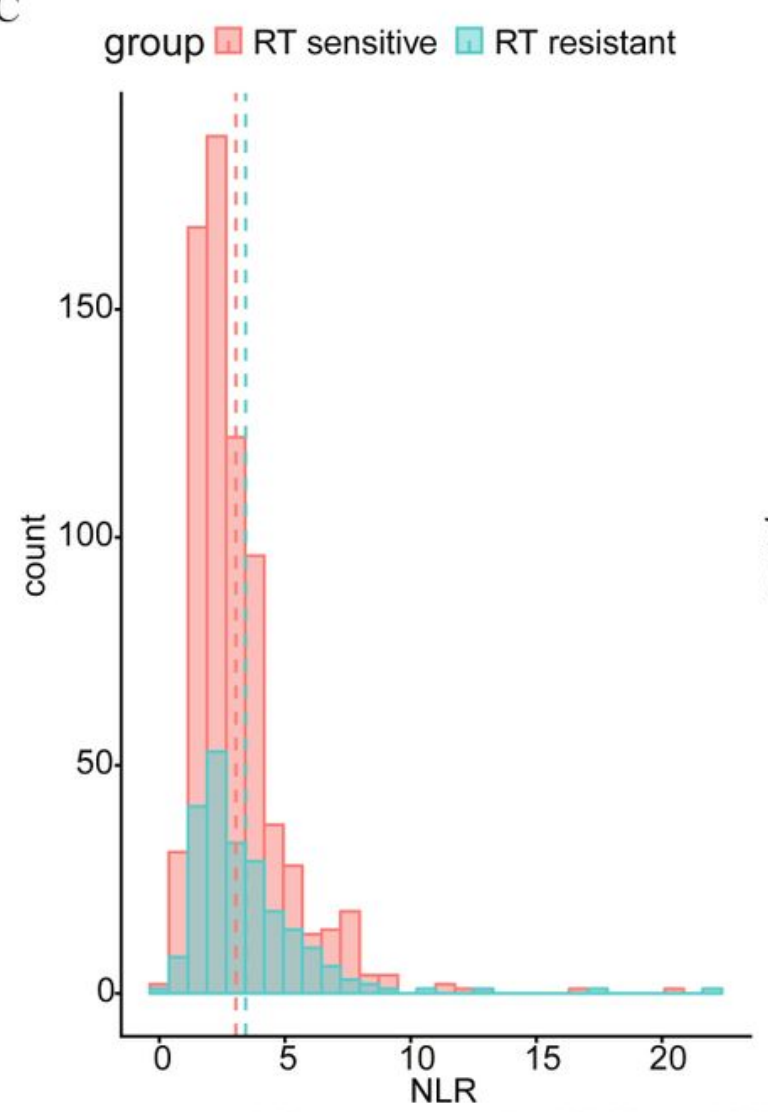

B

ROC curve

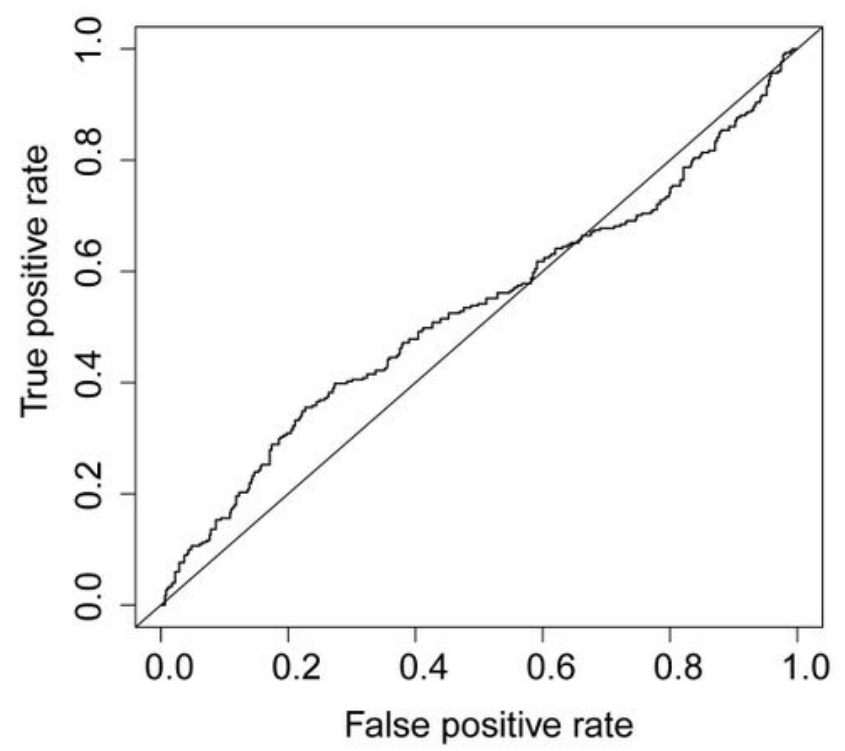

group $\square \mathrm{RT}$ sensitive $\square \mathrm{RT}$ resistant

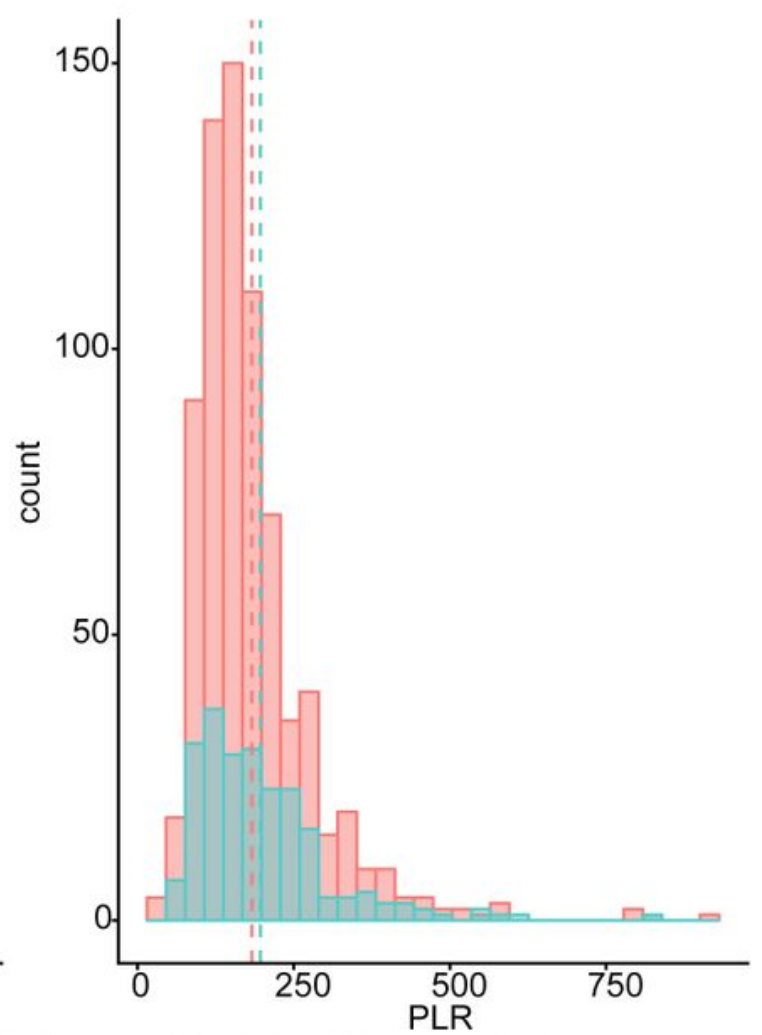

Historgrams for NLR and PLR, stratified by RT sensitivity

\section{Figure 1}

(A) ROC curve predicts prognostic value of NLR. The best critical value of NLR for predicting the efficacy of chemoradiotherapy was 2.91. The area under the curve was 0.561 . (B) ROC curve predicts prognostic of PLR The best critical value of PLR for predicting the efficacy of chemoradiotherapy was 174.8. The area under the curve was 0.531 . (C) Histograms of NLR and PLR in the radiotherapy sensitive and resistant groups. 
A

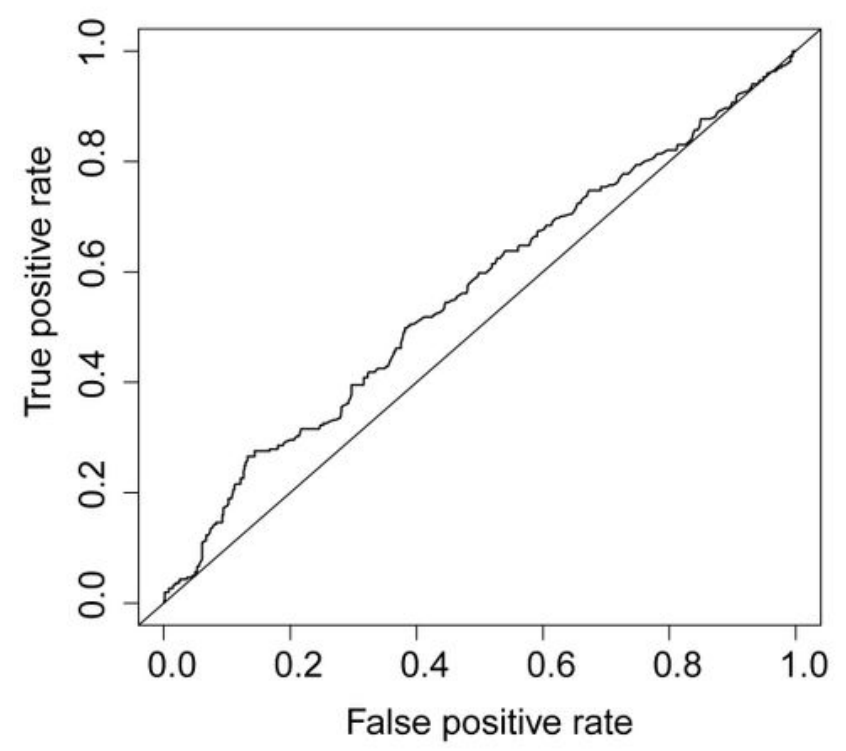

C
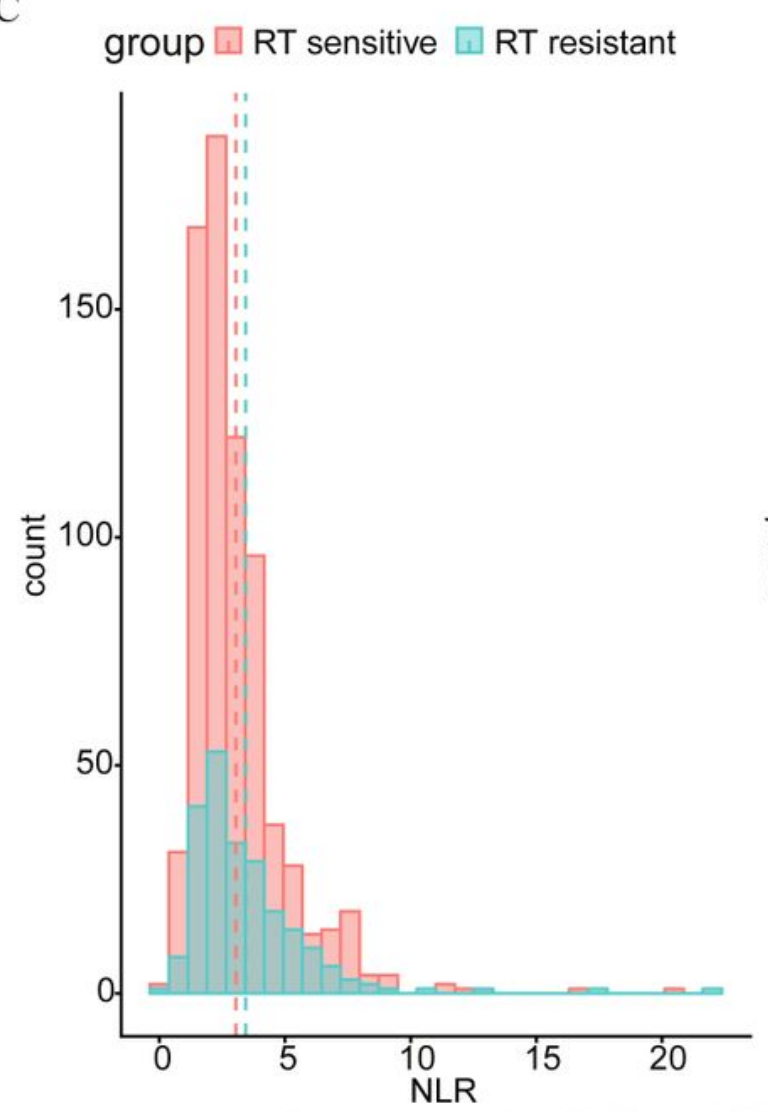

B

ROC curve

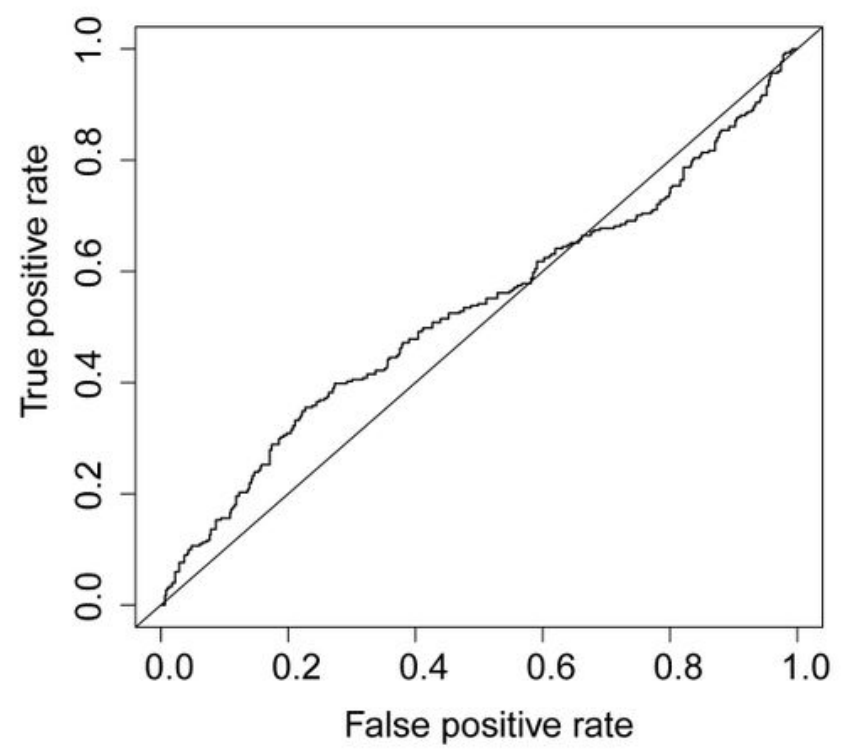

group $\square \mathrm{RT}$ sensitive $\square \mathrm{RT}$ resistant

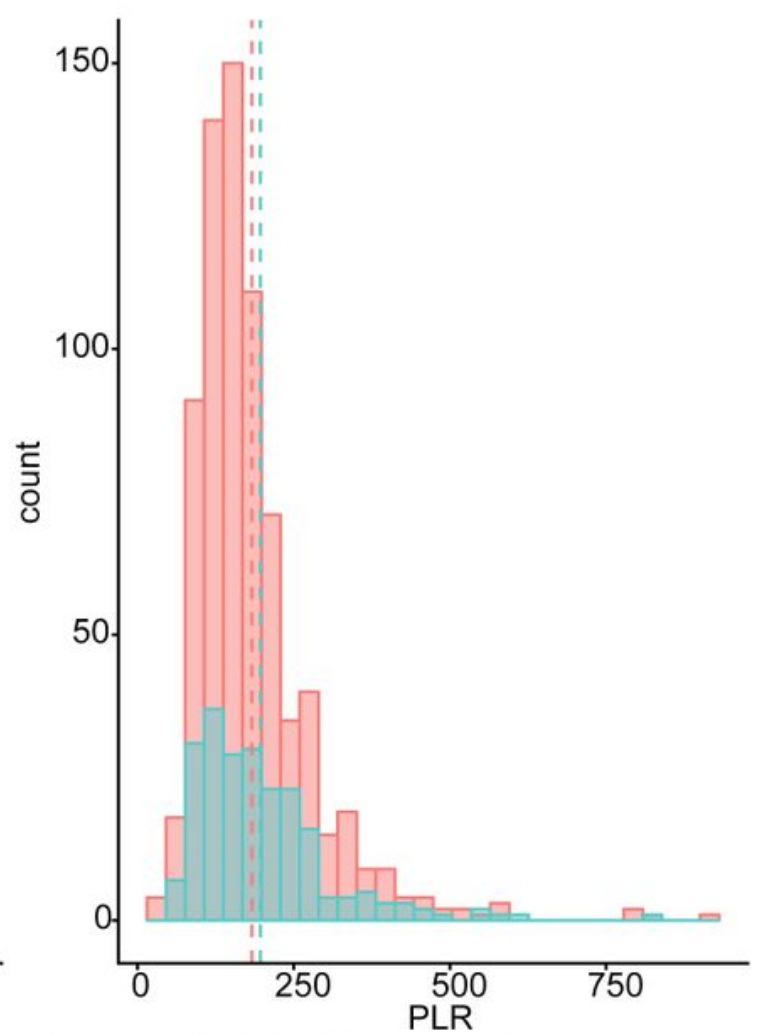

Historgrams for NLR and PLR, stratified by RT sensitivity

\section{Figure 1}

(A) ROC curve predicts prognostic value of NLR. The best critical value of NLR for predicting the efficacy of chemoradiotherapy was 2.91. The area under the curve was 0.561 . (B) ROC curve predicts prognostic of PLR The best critical value of PLR for predicting the efficacy of chemoradiotherapy was 174.8. The area under the curve was 0.531. (C) Histograms of NLR and PLR in the radiotherapy sensitive and resistant groups. 

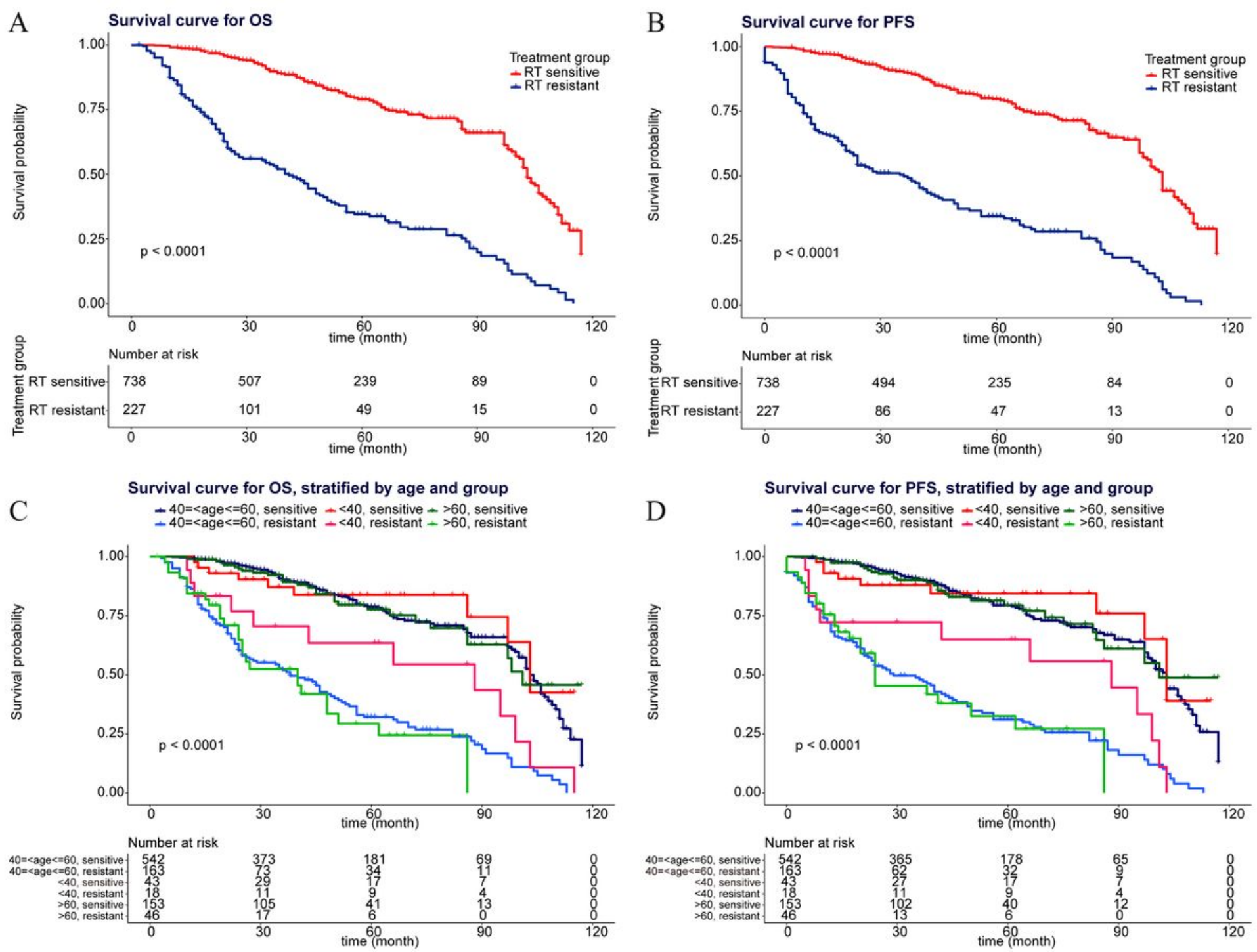

Figure 2

(A) Survival curves of overall survival in radiosensitive group and radioresistant group. (B) Survival curves of progression-free survival in radiosensitive group and radioresistant group. (C) Survival curves of overall survival in radiosensitive and radioresistant group stratified by age. (D) Survival curves of progression-free survival in radiosensitive and radioresistant group stratified by age. The survival rate of radiosensitive group was significantly higher than that of radioresistant group in OS and PFS. Similarly, in each age group, the survival rate of radiosensitive group was also significantly higher than that of radioresistant group. 

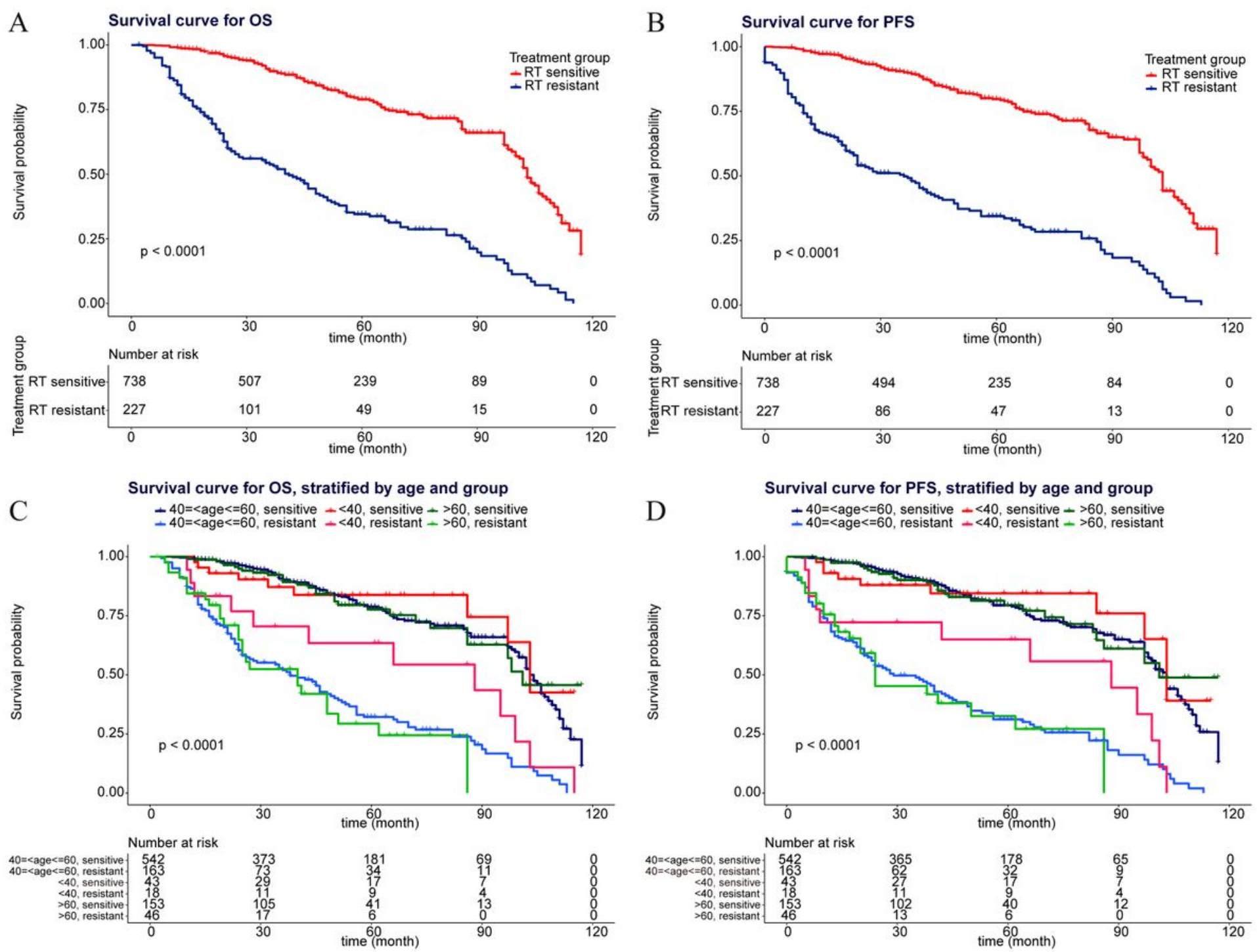

Figure 2

(A) Survival curves of overall survival in radiosensitive group and radioresistant group. (B) Survival curves of progression-free survival in radiosensitive group and radioresistant group. (C) Survival curves of overall survival in radiosensitive and radioresistant group stratified by age. (D) Survival curves of progression-free survival in radiosensitive and radioresistant group stratified by age. The survival rate of radiosensitive group was significantly higher than that of radioresistant group in OS and PFS. Similarly, in each age group, the survival rate of radiosensitive group was also significantly higher than that of radioresistant group. 